\title{
Widely Spaced Comb-Like Polymers of Which Teeth Appear on Every 11 to 15 Repeating Main Chain Atoms
}

\author{
Kenji YoKOTA and Tadamichi HIRABAYASHI \\ Department of Materials Science and Engineering, \\ Nagoya Institute of Technology, Gokisho-cho, Showa-ku \\ Nagoya 466, Japan
}

(Received August 30, 1985)

\begin{abstract}
KEY WORDS Comb-Like Polymer / Widely Spaced Comb-Like Polymer /
2-Hexadecylpropanediol-1,3 / Diacid Chloride / Polyester / Crystallization /
\end{abstract}

In our previous papers ${ }^{1,2}$ we synthesized some alternating butadiene-methacrylate copolymers and their hydrogenated copolymers having long alkyl or fluoroalkyl side chains and observed the crystallization of the side chains in spite of the wide spaces between them. (They appear on every six main chain carbon atoms.) We designated these copolymers as widely spaced comb-like polymers.

In this note we report briefly the crystallization of the hexadecyl side chains of the following polyesters. The polyesters, poly(2hexadecyltrimethylene alkanedioates), were synthesized from 2-hexadecylpropanediol-1,3 and various aliphatic diacid chloride.

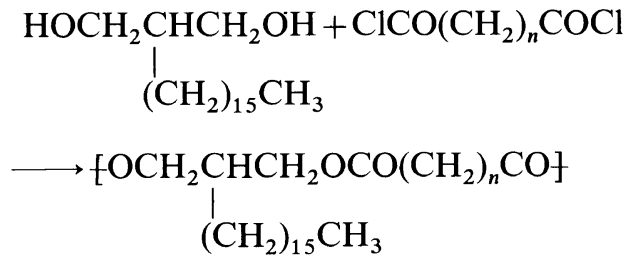

Diacid residues in eq 1 are from adipic to sebacic acid and therefore the teeth of these comb-like polymers (hexadecyl side chains) appear on every eleven to fifteen repeating main chain atoms. In this note, we investigated the influence of the spaces between teeth on the side chain crystallization of these widely spaced comb-like polymers. Magagnini and his coworkers reported the side chain crystallization of the alternating polymer of phthalic anhydride and octadecyloxirane ${ }^{3}$ and of the polyesters of eicosanediol-1,2 and three isomeric phthalic acids. ${ }^{4}$ Their polymers should also be classified as widely spaced comb-like polymers.

\section{EXPERIMENTAL}

\section{Monomers}

2-Hexadecylpropanediol-1,3 was synthesized by starting from diethyl malonate and hexadecyl bromide and reducing the intermediate, diethyl 2-hexadecylmalonate, with lithium aluminum hydride. The overall yield was $75 \%$. Recrystallization from benzene gave needle crystals. mp $86.0-86.3^{\circ} \mathrm{C}$. $200-\mathrm{MHz}$ ${ }^{1} \mathrm{H}$ NMR (in $\mathrm{C}_{6} \mathrm{D}_{6}$ at $75^{\circ} \mathrm{C}$ ) $\delta 0.97(\mathrm{t}, 3 \mathrm{H}$, $\mathrm{C}_{3}$ ), 1.40 (broad s, 30H, $\left.\left(\mathrm{C}_{2}\right)_{15}\right), 1.73$ (broad s, 1H, $\underline{\mathrm{H}}$ ), 1.97 (broad s, 2H, O$)$ ), and $3.70 \mathrm{ppm}\left(\mathrm{m}, 4 \mathrm{H}, \mathrm{C}_{2} \mathrm{OH}\right)$; IR ( $\mathrm{KBr}$ disc) 3320 (associated $\mathrm{OH}$ ), 1065 (primary $\mathrm{C}-\mathrm{O}$ ), 2900, 1466 and $722 \mathrm{~cm}^{-1}\left(\left(\mathrm{CH}_{2}\right)_{n}\right)$.

Anal. Calcd for $\mathrm{C}_{19} \mathrm{H}_{40} \mathrm{O}_{2}: \mathrm{C}, 75.93 \% ; \mathrm{H}$, $13.42 \%$. Found C, $75.72 \%$; H, $13.90 \%$.

Adipoyl (4), pimeloyl (5), suberoyl (6), azelaoyl (7), and sebacoyl (8) chlorides were 
Table I. Syntheses and properties of poly(2-hexadecyltrimethylene alkanedioates)

\begin{tabular}{|c|c|c|c|c|c|c|c|}
\hline Alkanedioate & $n^{\mathrm{a}}$ & $\frac{\text { Yield }}{\%}$ & $\mathrm{MW}^{\mathrm{b}}$ & DP & $\begin{array}{c}\begin{array}{c}\text { Freezing } \\
\text { temp }\end{array} \\
\mathrm{C}\end{array}$ & $\begin{array}{c}\text { Heat of } \\
\text { crystallization } \\
\text { kcal repeating unit }{ }^{-1} \mathrm{~mol}^{-1}\end{array}$ & $\begin{array}{l}\text { Number of } \\
\text { crystallizing } \\
\mathrm{CH}_{2} \text { groups }^{\mathrm{d}}\end{array}$ \\
\hline Adipate & 4 & 92 & 7000 & 17 & 18.5 & 6.39 & 9 \\
\hline Adipate & 4 & 96 & 14000 & 34 & 23 & 7.77 & 11 \\
\hline Adipate $^{\mathrm{e}}$ & 4 & 94 & 16000 & 39 & 23 & 8.07 & 11 \\
\hline Pimelate & 5 & 96 & 18000 & 42 & 13 & 7.32 & 10 \\
\hline Suberate & 6 & 97 & 16500 & 27 & 11 & 6.80 & 9 \\
\hline Azelate & 7 & 97 & 18000 & 40 & 5.5 & 8.53 & 12 \\
\hline Sebacate & 8 & 97 & 17000 & 36 & 24 & 9.16 & 12 \\
\hline Terephthalate & - & 96 & 12000 & 28 & 2 & 2.03 & 3 \\
\hline
\end{tabular}

a Number of $\mathrm{CH}_{2}$ groups in alkanedioate residue. This figure plus 7 gives the number of repeating main chain atoms with which the hexadecyl side chain appears.

b From the GPC peak top by reference to polystyrene standards.

c From the cooling mode DSC determination.

d Calculated by dividing the heat of crystallization by $0.735 \mathrm{kcal} \mathrm{CH}_{2}^{-1} \mathrm{~mol}^{-1}$.

e Polymerized in $N, N$-dimethylaniline instead of toluene.

commercially available reagents or prepared by the reaction of diacid and thionyl chloride. The figures in parentheses are referred to $n$ in eq 1 . Each diacid chloride was fractionated prior to the polymerization and a center fraction was used. Commercial terephthaloyl chloride was recrystallized from ligroin.

\section{Polymerization}

2-Hexadecylpropanediol-1,3 (0.01 mol) and a diacid chloride $(0.01 \mathrm{~mol})$ were weighed accurately in a $100 \mathrm{~cm}^{3}$ flask together with toluene $\left(100 \mathrm{~cm}^{3}\right)$. The flask was immersed in an oil bath and stirred under gentle reflux. At the beginning, as the diol melted, hydrogen chloride gas evolved vigorously. After one day of polymerization, the mixture was poured into methanol $\left(150 \mathrm{~cm}^{3}\right)$. The precipitated polyester was reprecipitated twice from a benzene solution into methanol and dried in vacuum.

\section{Measurement}

Differential scanning calorimetry (DSC) was determined on a Rigaku-Denki Thermoflex provided with a low temperature unit. About a $7 \mathrm{mg}$ sample was taken into an aluminum pan and covered with a lid. Both the heating and cooling rates were $10^{\circ} \mathrm{C} \min ^{-1}$. The $\mathrm{X}$-ray diffraction pattern was recorded with a solid sample using Ni-filtered $\mathrm{Cu}-K \alpha$ radiation on a Rigaku-Denki RAD II diffractometer. A solid sample was obtained by casting from a benzene solution of a polymer on a slide glass.

\section{RESULTS AND DISCUSSION}

Polyesters were obtained in almost quantitative yields. They were brittle wax or viscous liquids at room temperature. Table I shows their molecular weights and degrees of polymerization which are not so high. But, since the freezing temperatures for the three poly(2hexadecyltrimethylene adipate) samples of increasing molecular weights seemed to converge, the polyester samples were of enough high molecular weights for the present study. Polyester structures were confirmed by IR, ${ }^{1} \mathrm{H}$ and ${ }^{13} \mathrm{C}$ NMR spectra.

DSC traces for all polyester samples showed endothermic and exothermic peaks between 0 and $50^{\circ} \mathrm{C}$ on the heating and cooling mode determinations. The exothermic peaks appeared at $10-30^{\circ}$ lower than the endothermic 


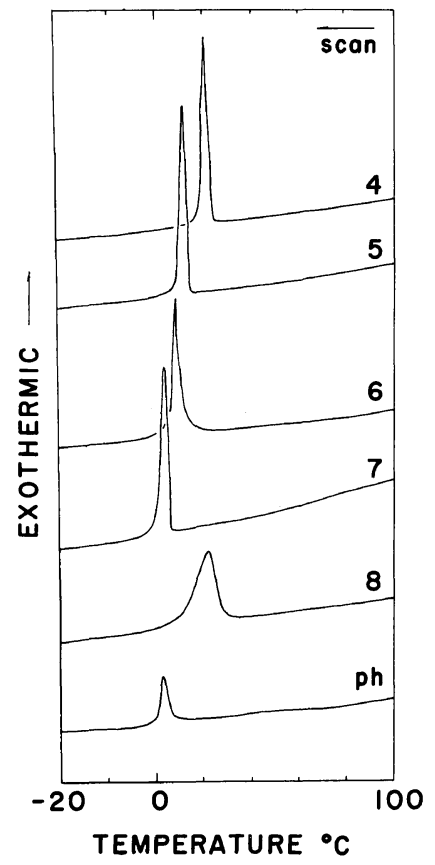

Figure 1. DSC traces of poly(2-hexadecyltrimethylene alkanedioate). Each figure is the number of methylene groups in the diacid residue; $\mathrm{ph}$ is the $p$-phenylene group.

peaks. The cooling mode traces are shown in Figure 1. Heats of crystallization were calculated from the peak areas (by calibration with the melting peak of a known weight of potassium nitrate) and are given in Table I.

$\mathrm{X}$-Ray diffraction patterns are shown in Figure 2 for typical polyesters. They showed peaks at about $2 \theta=20^{\circ}$ just as did the long alkyl methacrylate comb-like polymers and two types of widely spaced comb-like polymers in the previous paper. ${ }^{1}$ These peaks corresponded to the typical spacings of the hexagonal packing of long alkyl chains. Besides these peaks, they showed peaks at very low angles (about $3^{\circ}$ ).

IR spectra showed sharp single absorption bands at $720 \mathrm{~cm}^{-1}$ which should be assigned to the rocking mode $\mathrm{CH}_{2}$ vibrations of crystalline (hexagonal-packed) long alkyl chain compounds. ${ }^{5}$

The above results demonstrate that the side chains of the present widely spaced comb-like

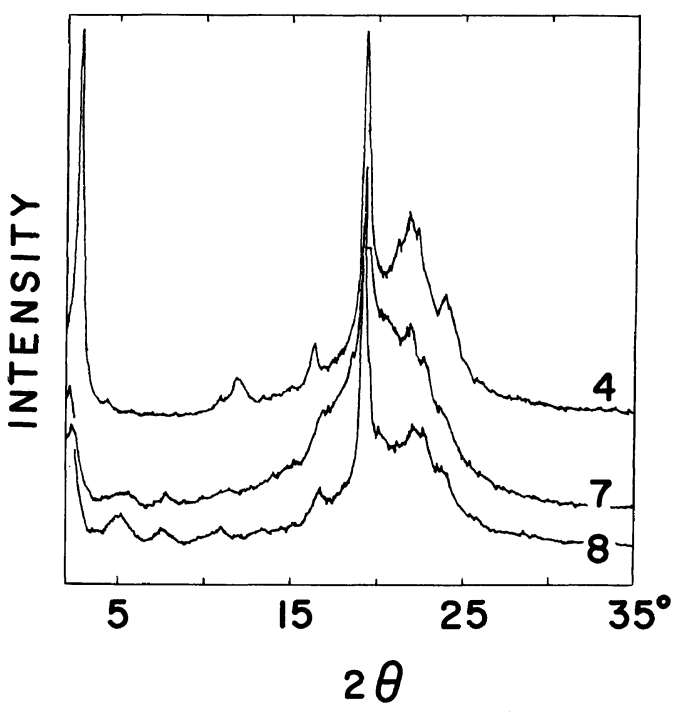

Figure 2. X-Ray diffraction patterns of poly(2hexadecyltrimethylene alkanedioate). Each figure is the number of methylene groups in the diacid residue.

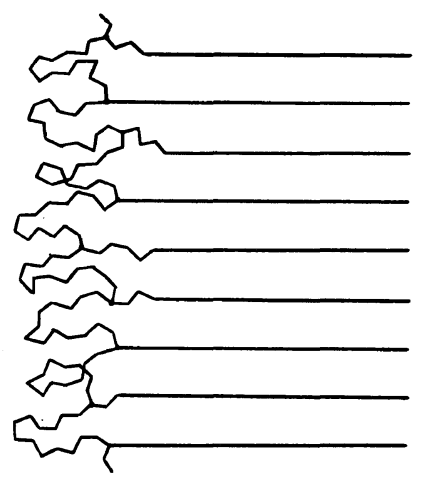

Figure 3. A possible structure of poly(2-hexadecyltrimethylene alkanedioate) whose side chains have crystallized.

polymers, poly(2-hexadecyltrimethylene alkanedioates), crystallize in spite of the wide spaces between them (up to fifteen repeating main chain atoms) as do those of conventional comb-like polymers. The flexible aliphatic polyester-type main chain allowed the side chains to be packed. Figure 3 shows a possible structure which contains crystallizing side chains and a coiling main chain (with some parts of side chains). The latter allows the side 
chains to be packed. The number of crystallizing $\mathrm{CH}_{2}$ groups was about ten. The less flexible terephthalate polymer gave a smaller number of crystallizing $\mathrm{CH}_{2}$ groups.

Aliphatic polyesters themselves are often crystalline and melt within the same temperature range. However, Batzer ${ }^{6}$ showed that side chain branching causes an appreciable decrease in melting temperature and some branched polyesters are liquid at room temperature. Therefore, the above observations should be ascribed to the crystallization of long alkyl side chains.

Acknowledgements. The authors thank Prof. Takeshi Mitsuda of Nagoya Institute of Technology for the X-ray determination. This work was supported by a Grand-in-Aid for Scientific Research from the Ministry of Education, Science and Culture of Japan.

\section{REFERENCES}

1. K. Yokota, T. Kougo, and T. Hirabayashi, Polym. J., 15, 891 (1983).

2. K. Yokota and T. Hirabayashi, Polym. J., 17, 991 (1985).

3. F. Andruzzi, D. Lupinacci, P. L. Magagnini, and A. L. Segre, Polym. Bull., 11, 241 (1984).

4. F. Andruzzi, C. Barone, D. Lupinacci, and P. L. Magagnini, Makromol. Chem., Rapid Commun., 5, 603 (1984).

5. D. Chapman, J. Chem. Soc., 4489 (1957).

6. H. Batzer and F. Wiloth, Makromol. Chem., 6, 60 (1951). 